\title{
OBESITY IN CHILDHOOD AND ITS EFFECTS
}

\author{
O. H. WolfF, M.A., M.D., F.R.C.P., D.C.H. \\ Reader in Padiatrics and Child Health, Children's Hospital, Birmingham, 16
}

IN $195^{\circ}$ a clinic for the treatment of obesity in children was started at the Children's Hospital, Birmingham. The first roo children to attend this clinic form the basis for our studies of the effects of overnutrition on the development of children and of the natural history of childhood obesity (Wolff, r955; Lloyd, Wolff and Whelen, 196r).

\section{Birth Weight}

Neither the mean birth weight of $7 \mathrm{lb} .4 \mathrm{oz}$. nor the distribution curve of the birth weights differed significantly from those of the general population.

\section{Prognosis of Childhood Obesity}

At present it is not known how often a fat infant grows into a fat child. The fashion in teaching medical students about infant feeding is to stress the dangers of under-feeding and to minimize those of over-feeding, if indeed we admit that over-feeding has any dangers. If a prospective study of overweight infants showed that many remained overweight into the later years of childhood, we should have to modify our teaching. Widdowson and McCance (1960) have shown that in the rat the food intake during the first few days of life plays an important role in determining the food intake and body weight of the animal for the rest of life. It is conceivable that in the human, too, the complicated appetiteregulating mechanism may be conditioned or ' set' for the years to come during the early months of the infant's life.

Our studies of the natural history of childhood obesity (Lloyd, Wolff and Whelen, r96r) do not cover the period of infancy but they show that there is a marked tendency for childhood obesity to persist into adult life; or, in other words, theappetite-regulating mechanism becomes conditioned in childhood and it is very difficult to reset the control. Thus, at the initial examination in 1950 the girls were on average $58 \%$ overweight for their height and none was less than $20 \%$ overweight. Between $195^{\circ}$ and $195^{1}$ most of them

\footnotetext{
Abridged version of a paper read at a course on ' Growing Points in Pædiatrics', held by the University of Cambridge School of Clinical Research and Postgraduate Medical Teaching, April 1962.
}

attended the clinic regularly for treatment and the mean overweight of the group fell significantly to $30 \%$. However, thereafter a significant relapse occurred in the group as a whole; and, at the last examination in 1959, when the mean age of the group was $17 \frac{1}{2}$ years, more of the girls were grossly overweight (over $80 \%$ ) than at the first examination, and only about a quarter were less than $20 \%$ overweight. The boys showed essentially the same trend.

The boys and girls who at the last examination were over 20 years were on average fatter than those below 20. For the girls this difference was striking, the under 20's having a mean overweight of $41 \%$, and the over 20 's of $66 \%$. These findings suggest that with advancing years there is a tendency for the obesity to become more marked.

The children who at the first examination were grossly overweight (more than $80 \%$ ) were still significantly fatter at the final examination than those who at first were least overweight (less than $40 \%$ ).

With the recognition that childhood obesity is likely to persist into adult life, when it will have an influence on morbidity and mortality, its treatment takes on new importance. Success in short-term management is of little consequence. In our study the rate at which the children lost weight during the period of intensive therapy bore no relationship to the degree of overweight at the final examination. The children who under intensive treatment had returned to near-normal weight in the long run fared no better than those whose immediate response had been less satisfactory and four-fifths of these early successes later relapsed. Longcontinued supervision appears to be the essence of management.

\section{Effects of Over-nutrition \\ Height}

Widdowson and McCance (1960) have shown that in the rat linear growth can be accelerated by increasing food intake from the early days of life. In these experimental animals length kept pace with weight so that they did not become obese. Wolff (1955) has shown that obese children are significantly taller than normal children from various social classes but not significantly taller 
than children of the professional class. If, then, height gain can be accelerated by above-average or even excessive nutrition it is not surprising that a reduction in food intake will lead to a slowing down of growth in height. Thus the obese children, who during treatment lost weight rapidly, gained in height about $20 \%$ less than expected, whereas those who failed to lose or even continued to gain weight continued to gain in height 5 to $10 \%$ more than expected (Wolff, 1955). Between these extremes a close inverse correlation existed between rate of weight loss and height gain.

If the expected result of overnutrition is increased height gain then the combination of obesity with an unexpectedly low height should lead one to suspect the presence of a factor counteracting this growth stimulus, for example, deficiency of thyroxine.

\section{Age at the Onset of Puberty}

In obese boys and girls the onset of puberty occurs on average about a year sooner than in the general population (Wolff, I955).

\section{Skeletal Maturation}

Overnutrition accelerates skeletal maturation and even in the obese child who is dwarfed skeletal maturation is usually found to be normal for the child's age, if not advanced.

\section{Ultimate Height Reached}

Using Tanner's (1958) standard for English children for comparison, we (Lloyd, Wolff and Whelen, 196r) found that the height of the obese individuals after puberty was a little below the standard. We argued that overnutrition had accelerated skeletal maturation to such an extent that relatively early epiphyseal fusion had resulted in an ultimate height a little below standard. After we had published these findings in the British Medical Fournal in July $196 \mathrm{I}$, Dr. C. O. Carter wrote a letter to the editor, entitled 'The Englishman's Height ', in which he stressed the difficulty of knowing what average adult height is. He suggested from recent army data that 68.I in. might be a likely figure for the boys. If this figure is confirmed we should have to conclude that the ultimate height of the obese boys, who before the onset of puberty had been of above-average height, does not differ significantly from average.

\section{Mental and Psychological Development}

Tanner (1955) has shown that at the same chronological age those who are physically more advanced score higher in mental tests than those who are less advanced. As most obese children are physically advanced in respect of height and puberal development, one might suspect that toy would also be advanced in mental development But I know of no systematic study of their intelligence to confirm or refute this suspicion.

Bruch (1943) stresses the importance of ergotional factors in the causation of obesity but says little about the effects of overnutrition on psyche. I am often impressed by the embarrassment these children feel about their appeararce. They are teased by their school-mates and brothers and sisters and many withdraw from the company of other children and spend long periods sittittg, watching television and eating. They become embarrassed to engage in more active pursuits

\section{Physical Activity}

In many cases the enormous accumulation of interferes with normal activity. This inactivity gुas important clinical implications. Until recentlse was suggested that nothing was gained by advising the overweight individual to become more active because-it was said-more exercise would simply increase appetite. However, Mayer, Marshill, Vitale, Christensen, Mashayekhi and Stare (19 4 ) have recently shown in the rat that this relationship between exercise and calorie intake golds good only over the range of moderate acterigy. When activity is reduced below a certain calorie intake increases and weight is ganed. Passmore (1958) concluded that the same applied to the dog. In man, Mayer (1959) showed that, 尹्?n average, industrial workers engaged in modergte activity had the lowest mean calorie intake. Thisse engaged in heavy work naturally had a higher intake but had the same average body weight the moderately active workers. On the other hand, the sedentary workers had a higher intake than moderately active workers and consequently had a higher mean weight than either the moderately very active workers. Thus neither in the management of our obese patients, nor when we discuss xtiology, can we afford to neglect this aspectofof physical activity.

\section{Conditions Found in Association with Childhood Obesity}

I now want to turn to one or two of the normalities which are occasionally found in association with childhood obesity. When obesityis found together with another condition there is a tendency to postulate the existence of a syndrorie. I want to suggest that before doing so we mist consider three other possibilities: (I) chaffee association; (2) the associated condition predisposing to the development of obesity; (3) obesity predisposing to the development of the associated condition. 


\section{Mental Defect}

I shall take the association of obesity with mental defect as an example. The incidence of mental deficiency amongst school children is of the order of 2 to $3 \%$, and $3 \%$ is a conservative estimate of the incidence of obesity amongst school children. The association of obesity and mental deficiency would then be expected to occur by chance once in every 1,000 school children, an incidence comparable to that of mongolism or congenital dislocation of the hips. Amongst obese children one may expect an incidence of mental deficiency of $I$ in 30 .

Moreover, there are reasons for believing that mental deficiency may predispose to the development of obesity. Mental defectives are characteristically inactive. Further, there are psychological factors which predispose the mentally retarded child to be given an excess of food. Their parents have great difficulty in showing them their love, many of the usual channels being blocked. Also, many of these parents suffer from feelings of guilt. Food then becomes the vehicle for love and the means of appeasing the parents' guilt feelings. Finally, as a group, they are below average height. If then, because of some constitutional growthlimiting factor, these children cannot respond to overnutrition with increased growth in height, protein calories, which would otherwise be used for extra protein anabolism, will be laid down as fat. Thus one may expect to see the association of obesity and mental defect even more frequently than can be acccunted for by chance.

\section{Cryptorchidism}

Another condition that is occasionally found in obese children is cryptorchidism and a lesion in the region of the hypothalamus and pituitary gland is then too often postulated to account for both conditions. The incidence of bilateral cryptorchidism in childhood is of the order of $1 \%$. Ultimately descent will occur in about two thirds of cases (Thompson, 1955). One might then expect obesity and bilateral cryptorchidism to coexist by chance in I out of 3,300 boys; or I out of every 100 obese boys might be expected to have bilateral cryptorchidism. In my experience this association is not much more frequent than could be explained on grounds of chance.

\section{Metabolic and Endocrine Considerations}

I have described the effects of overnutrition on growth and sexual development but I have not said anything about the mechanisms by means of which overnutrition achieves these effects. These have not yet been worked out in detail and my remarks are speculative. It seems likely that overnutrition has an effect on, and acts through stimulation of, anterior pituitary and adreno- cortical function. Thus, fat children on average excrete more 17-ketogenic and 17-hydroxysteroids than do children of normal weight (Brit. med. F., 1961). When they are put on a restricted diet their urinary 17 -ketogenic steroid excretion quickly returns to normal. In most obese children one must, therefore, regard the increased adrenocortical function as the result of overnutrition rather than as the cause of the obesity.

Renewed interest is now being taken in the intermediary metabolism of the obese patient (Kekwick, I960). One might almost predict that chronic overnutrition leading to an enormous increase in total body fat would result in important changes in intermediary metabolism. Thus recently Rabinowitz and Zierler (I96r) adduced evidence in favour of hyperinsulinism occurring as an adaptive phenomenon in obesity. In this context it is interesting that Weill and Bernfeld (1957), in a study of glucose tolerance curves in obese children, found that about one third had impaired glucose tolerance. It is tempting to speculate that after a period of hyperinsulinism exhaustion of the beta cells of the islets of Langerhans may occur and the occasional coexistence of diabetes and obesity might be anticipated; again we should desist from postulating a syndrome until chance and the effect of overnutrition have been considered. In two thirds of Weill's and Bernfeld's patients with abnormal glucose tolerance the curves returned to normal during weight reduction.

It is important that when a particular metabolic deviation from the normal is detected the investigation should be repeated when the patient has regained and is maintaining normal weight. Otherwise it will be impossible to differentiate cause and effect.

\section{Summary}

Overnutrition has important effects on growth and the onset of puberty. The mechanisms through which these effects are mediated are not yet clear but the anterior pituitary gland, adrenal cortex and the islets of Langerhans are probably involved. Adaptive changes in intermediary metabolism are also likely and need further study.

When childhood obesity is associated with other abnormalities, such as mental deficiency, cryptorchidism or diabetes, it is essential to consider the possibilities of: (a) chance association; (b) the obesity predisposing to the development of the associated condition; and $(c)$ the associated condition predisposing to the development of obesity before postulating the existence of a syndrome. True syndromes comprising obesity exist but are rare.

I am grateful to Professor D. V. Hubble and Dr. June K. Lloyd for helpful discussions. 


\section{REFERENCES}

British Medical Fournal (196I): Leader: Corticosteroid Excretion in Obesity, ii, 949.

Bruch, H. (1943): Psychiatry Aspects of Obesity in Children, Amer. F. Psychiat., 99, 752.

CARTER, C. O. (1961): The Englishman's Height, Brit. med. F., ii, 5 I8.

KEKWICK, A. (I960): On Adiposity, Ibid., ii, 5196. Weight, Lancet, ii, 145.

MAYER, J. (I959): Sixth Spring Symposium on Overweight and Underweight, the Michigan Academy of Genesal

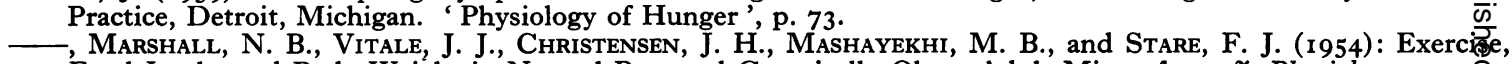
Food Intake and Body Weight in Normal Rats and Genetically Obese Adult Mice, Amer. F. Physiol., 177, 549.

PASSMORE, R. (1958): A note on the Relation of Appetite to Exercise, Lancet, i, 29.

RabinOwITZ, D., and ZIERLER, K. L. (1961): Forearm Metabolism in Obesity and its Response to Intra-arterial Insulin, Ibid., ii, 690.

TANNER, J. M. (1955): ' Growth at Adolescence'. Oxford: Blackwell.

(1958): In 'Modern Trends in Pædiatrics', edited by A. Holzel and J. P. M. Tizard, p. 325. London: Butterworth.

Thompson, W. O. (1955): In 'A Textbook of Medicine', edited by Russell L. Cecil and Robert F. Loeb, 9th editigh, p. 804. London: W. B. Saunders Company, Philadelphia.

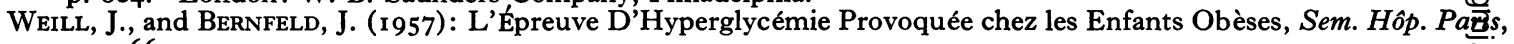

33, I66I.
WidDowson, Elsie, M., and McCANCE, R. A. (1960): Some Effects of Accelerating Growth: I-General Somatc Development, Proc. roy. Soc. B, 152, i 88 .

WolfF, O. H. (1955): Obesity in Childhood, Quart. F. Med., 24, ro9. 